\title{
Effect of diversified and staged health education on the compliance of elderly patients with coronary heart disease
}

\author{
Zi Shan ${ }^{1}$, Hong Huang ${ }^{1}$, Sanhui Tang ${ }^{2}$ \\ ${ }^{1}$ Department of Integrated Traditional Chinese Medicine and Western Medicine, Hunan Provincial People's Hospital (The First Affiliated Hospital \\ of Hunan Normal University), Changsha, China; ${ }^{2}$ Nursing Department, Hunan Provincial People's Hospital (The First Affiliated Hospital of Hunan \\ Normal University), Changsha, China \\ Contributions: (I) Conception and design: Z Shan, S Tang; (II) Administrative support: S Tang; (III) Provision of study materials or patients: Z Shan, \\ H Huang; (IV) Collection and assembly of data: Z Shan, H Huang; (V) Data analysis and interpretation: Z Shan, H Huang, S Tang; (VI) Manuscript \\ writing: All authors; (VII) Final approval of manuscript: All authors. \\ Correspondence to: Sanhui Tang. Nursing Department, Hunan Provincial People's Hospital (The First Affiliated Hospital of Hunan Normal \\ University), Changsha 410016, China. Email: T13908469736@163.com.
}

Backgrounda To explore the effect of diversified and staged health education on the compliance of elderly
patients with coronary heart disease (CHD).
Methods: A total of 180 elderly patients with CHD were randomly divided (using computerized random
grouping) into a control group ( $\mathrm{n}=90)$ and study group $(\mathrm{n}=90)$ between January 2018 and December 2019 in
the Department of Integrated Traditional Chinese Medicine (TCM) and Western Medicine in our hospital.
The control group was given routine health education, while the study group was supplemented with
diversified and staged health education on this basis. After the intervention, the health knowledge mastery of
CHD, compliance, self-care ability, incidence of adverse events, and life quality were compared between the
2 groups. Results: After the intervention, the health knowledge mastery of CHD, total compliance, and self-care ability scores in the study group were significantly higher than those in the control group $(\mathrm{P}<0.05)$. The incidence rate of adverse events in the study group was significantly lower than that in the control group $(\mathrm{P}<0.05)$. After 3-month follow-up, it was found that the life quality score in the study group was significantly higher than that in the control group $(\mathrm{P}<0.05)$.

Conclusions: Diversified and staged health education for elderly patients with CHD can improve the health knowledge mastery of the disease, self-care ability, compliance, life quality, and subsequently reduce adverse events.

\begin{abstract}
Keywords: Elderly patients with coronary heart disease (elderly patients with CHD); diversified and staged health education; compliance; life quality
\end{abstract}

Submitted Sep 14, 2020. Accepted for publication Oct 30, 2020.

doi: 10.21037/apm-20-1995

View this article at: http://dx.doi.org/10.21037/apm-20-1995

\section{Introduction}

Coronary heart disease (CHD) is a common cardiovascular disease with various causes, high prevalence and mortality, and greatly negatively impacts the health of Chinese residents. With the rapid growth of the aging population in China, the elderly have gradually become the high risk group of CHD. Therefore, active diagnosis and treatment of elderly coronary heart disease is particularly important. Drug therapy is a conventional method for the treatment of CHD in the elderly. However, CHD is a complex condition, with no typical symptoms, various complications such as myocardial infarction and heart failure, a long course, and various types of medication directly increase the 
difficulty of clinical diagnosis and treatment, and the risk of death $(1,2)$. Studies have shown that the causes of death in elderly patients with CHD are related to many factors, such as unhealthy lifestyle, lack of awareness of the disease, and poor compliance (3-5). Therefore, strengthening the health education of elderly patients with CHD has significance for its prognosis. However, routine health education cannot achieve satisfactory results due to the individual differences of the patients. At present, some scholars have explored and analyzed the health education of elderly patients with CHD. Studies have shown that health education promotes disease control in elderly patients with CHD (6-8). Diversified health education can improve self-management, self-efficacy, and reduce rehospitalizations rate in elderly patient groups (9-12). In recent years, patients' level of awareness about CHD has been increasing, and their needs for health knowledge has amplified in intensity. Therefore, the importance and necessity of diversified and staged health education have become increasingly recognized, especially in cardiovascular medicine. Strengthening diversified and staged health education for elderly patients with CHD has become the key to ensure the compliance of patients and improve clinical outcome and prognosis. In this study, elderly patients with CHD admitted to our hospital were randomly selected as study participants to compare the effects of routine education and diversified and staged health education, aiming to solve the problem of poor compliance of elderly patients with $\mathrm{CHD}$, strengthen the treatment effect, and promote the healthy development of the body.

We present the following article in accordance with the CONSORT reporting checklist (available at http://dx.doi. org/10.21037/apm-20-1995).

\section{Methods}

\section{General data}

The included cases were approved by the ethics committee of our hospital. All procedures performed in this study involving human participants were in accordance with the Declaration of Helsinki (as revised in 2013). Informed consent was taken from all the patients. A total of 180 elderly patients with CHD admitted to the Department of Integrated Traditional Chinese Medicine (TCM) and Western Medicine in our hospital from January 2018 to December 2019 were randomly selected and divided into a control group $(n=90)$ and study group $(n=90)$. There were several inclusion criteria: (I) in a stable condition, lucid, and good compliance; (II) aged 60-89 years old; (III) in accordance with the criteria in the "Guidelines for the Diagnosis and Treatment of Stable Coronary Heart Disease" (13); (IV) participants and/or their families were informed and participated voluntarily. There were also several exclusion criteria: (I) difficulties in understanding, expression, or writing; (II) previous history of senile dementia; (III) comorbidities such as psychological diseases, liver and kidney dysfunction, or malignant tumors; (IV) withdrew voluntarily due to personal reasons during the study.

\section{Education methods}

The control group undertook routine health education. After admission, doctors provided health education to the patients by means of verbal education and publicity boards. The education was mainly based on the basic knowledge of CHD, such as etiology, clinical manifestations, complications, harmfulness, treatment methods, nursing points, and daily precautions, aiming to deepen their understanding of the disease. The patients were guided to foster their health by maintaining a healthy psychological state, taking medicine regularly, adjusting diet structure scientifically, participating in appropriate outdoor activities, giving up smoking, and limiting alcohol. At the same time, the participants were instructed to regularly reexamine, and to develop a healthy lifestyle with regular sufficient rest.

The study group was provided with diversified and staged health education on the basis of the routine education. A group for the delivery of the diversified and staged health education was established. The members included a doctor, a head nurse, and several other nurses, who received systematic, unified, and standardized training, and were required to pass the training assessment. They drafted the stage goals and specific content in combination with their previous work experience and the clinical characteristics of the participants. Intervention education was performed in stages. In the first stage, the goal was to deepen the patients' understanding of CHD. On the day of admission, the members actively talked with the participants, focusing on the purpose and clinical significance of diversified and staged health education in order to garner their cooperation. Afterwards, the patients were provided with detailed information about CHD and health education materials, with consideration given to the differences in age, education level, understanding of CHD, 
Table 1 Contents of health education

\begin{tabular}{lll}
\hline Time & Content & Objective \\
\hline $\begin{array}{l}\text { The first } \\
\text { stage }\end{array}$ & $\begin{array}{l}\text { Explain the purpose and significance of diversified and phased health education; } \\
\text { introduce disease knowledge (etiology, performance, harmfulness, adverse } \\
\text { consequences, prevention knowledge, risk factors) by issuing health education } \\
\text { materials }\end{array}$ & $\begin{array}{l}\text { To deepen the patient's } \\
\text { understanding of the disease }\end{array}$ \\
$\begin{array}{l}\text { The second } \\
\text { stage }\end{array}$ & $\begin{array}{l}\text { Consolidate the first stage of education content; to consolidate the knowledge of } \\
\text { coronary heart disease (diet guidance, medication knowledge, exercise, risk factors, }\end{array}$ & $\begin{array}{l}\text { To strengthen the knowledge of } \\
\text { disease health prevention }\end{array}$ \\
self-monitoring of disease, etc.); peer education and personal experience &
\end{tabular}

and acceptance ability. Participants with learning difficulties had their questions answered patiently. In the second stage, the goal was to strengthen their knowledge of CHD and its prevention. First, the patients consolidated and reviewed the content learned in the first stage. Then, they continued to be educated by means of videos and pictures, focusing on the knowledge of CHD including dietary guidance, medication, exercise, risk factors, self-monitoring of the condition, and others. If necessary, patients with successful treatment histories of similar diseases were invited to share their own experience $(0.5-1 \mathrm{~h}$ each time), which was a kind of peer education to further enhance the confidence of the patients in rehabilitation. In the third stage, the focus was individualized health education. The knowledge mastery of the patients was investigated to assess the effect of the education. On this basis, individualized health education was carried out for those with unsatisfactory health education results. Targeted solutions were created to accommodate any existing problems of participants. The importance of self-care and compliance was emphasized, and the discharged patients were invited to join the WeChat group (named "xin xin xiang rong") to share their experience with each other, to foster accountability for and improvement of bad living habits and to promote the personal health (Table 1).

\section{Observation indicators}

(I) A self-made questionnaire, "Elderly Patients with Coronary Heart Disease Health Knowledge Mastery Questionnaire", was used to evaluate the knowledge mastery after intervention (treatment + health education) in the two groups. The questionnaire included the cognition of the disease, health care, adverse events, and other items, with a total score of 100 points. A score of $100-80$ was considered as complete mastery, 79-60 as partial mastery and $<60$ as no mastery. Total mastery rate $=$ complete mastery rate + partial mastery rate.

(II) The exercise of self-care agency (ESCA) scale (8) was used to evaluate the self-care ability before and after intervention in the two groups. It included 43 items in 4 dimensions including health knowledge level, selfcare responsibility, self-concept, and self-care skill, with a total score range of $0-172$ points. Each item was 1-4 points, and the higher the score, the better the self-care ability.

(III) A self-made questionnaire, "Elderly People with Coronary Heart Disease Compliance Questionnaire", was used to evaluate the compliance of the patients after intervention in the 2 groups. It included regular medication, reasonable diet, regular reexamination, exercise, and other items, with a total score of 100 points. A score of $100-80$ points was considered as complete compliance, 79-60 as partial compliance and $<60$ as non-compliance. Compliance rate $=$ complete compliance rate + partial compliance rate.

(IV) The adverse events in the 2 groups were counted, including heart failure, cardiogenic shock, sudden cardiac death, arrhythmia, acute myocardial infarction, and others.

(V) The Generic Quality of Life Inventory 74 (GQOLI-74) (9) was used to evaluate the quality of life. It included 4 dimensions-social function, physical function, material life status, and psychological function, with a score range of $80-400$ points, and the higher the score, the better the quality of life. 
Table 2 Comparison of the health knowledge mastery

\begin{tabular}{lcccc}
\hline Group & Complete mastery & Partial mastery & No mastery & Total mastery \\
\hline Study group $(\mathrm{n}=90)$ & $36(40.00)$ & $49(54.44)$ & $5(5.56)$ & $85(94.44)$ \\
Control group $(\mathrm{n}=90)$ & $30(33.33)$ & $41(45.56)$ & $19(21.11)$ & $71(78.89)$ \\
U-value & - & - & - & 7,512 \\
P value & - & - & 0.046 \\
\hline
\end{tabular}

Values are $n(\%)$.

Table 3 Comparison of the self-care ability

\begin{tabular}{lcc}
\hline \multirow{2}{*}{ Group } & \multicolumn{2}{c}{ ESCA score (points) } \\
\cline { 2 - 3 } & Before intervention & After intervention \\
\hline Study group $(\mathrm{n}=90)$ & $97.31 \pm 11.05$ & $149.33 \pm 20.10^{\#}$ \\
Control group $(\mathrm{n}=90)$ & $96.20 \pm 10.13$ & $120.45 \pm 15.19^{\#}$ \\
$t$-value & 0.702 & 10.875 \\
P value & 0.483 & 0.000 \\
\hline
\end{tabular}

Values are mean $\pm \mathrm{SD} .{ }^{*} \mathrm{P}<0.05$ vs. before intervention. ESCA, exercise of self-care agency.

\section{Statistical analysis}

The SPSS 25.0 software (IBM Corp., Armonk, NY, USA) was used for statistical analysis. Measurement data were expressed as mean \pm standard deviation (SD), and the differences between the 2 groups were compared by $t$-test. The enumeration data were expressed as frequency (n) and percentage (\%), and the differences between the groups were analyzed by chi-squared $\left(\chi^{2}\right)$ test. Two independent samples (ranked data) were analyzed by Mann-Whitney test. $\mathrm{P}<0.05$ indicated a significant difference.

\section{Results}

\section{Baseline characteristics}

A total of $180 \mathrm{CHD}$ patients were randomly divided into a control group $(n=90)$ and study group $(n=90)$. The control group consisted of 49 males and 41 females, with a mean age of $75.20 \pm 11.11$ years, including 20 cases with an education level of college and above, 15 high school, and 55 junior high school and below. The study group consisted of 51 males and 39 females, with a mean age of $76.15 \pm$ 12.07 years, including 23 cases with an education level of college and above, 18 high school, and 49 junior high school and below. Statistical analysis determined that there was no statistical differences in the baseline data between the 2 groups $(\mathrm{P}>0.05)$; the groups were comparable.

\section{Comparison of the bealth knowledge mastery}

The health knowledge mastery was compared between the 2 groups after intervention (Table 2). After the intervention, the mastery in the study group was significantly higher than that in the control group $(\mathrm{P}<0.05)$.

\section{Comparison of the self-care ability}

The ESCA scores were used to assess self-care ability in the 2 groups before and after intervention (Table 3). There was no significant difference in ESCA scores before intervention between the 2 groups $(\mathrm{P}>0.05)$. After intervention, the scores of the 2 groups were higher than those before intervention, and the score of the study group was significantly higher than that of the control group $(\mathrm{P}<0.05)$.

\section{Comparison of the compliance}

After intervention, the compliance in the study group was significantly higher than that in the control group $(\mathrm{P}<0.05)$ (Table 4).

\section{Comparison of the incidence of adverse events}

After intervention, the incidence of adverse events in the study group was significantly lower than that in the control group $(\mathrm{P}<0.05)$ (Table 5).

\section{Comparison of the quality of life during the 3-month follow-up}

The quality of life of CHD patients was assessed using the GQOLI-74 score (Table 6). The GQOLI-74 score in the 
Table 4 Comparison of the compliance

\begin{tabular}{lccc}
\hline Group & Compliance & Non-compliance & $\chi^{2}$ value \\
\hline Study group $(n=90)$ & $87(96.67)$ & $3(3.33)$ & 9.944 \\
Control group $(n=90)$ & $74(82.22)$ & $16(17.78)$ & 0.002 \\
\hline
\end{tabular}

Values are $n(\%)$.

Table 5 Comparison of the incidence of adverse events

\begin{tabular}{|c|c|c|c|c|c|}
\hline Group & Heart failure & Acute myocardial infarction & Arrhythmia & Cardiogenic shock & Total incidence \\
\hline Control group $(n=90)$ & $5(5.56)$ & $3(3.33)$ & $3(3.33)$ & $2(2.22)$ & $13(14.44)$ \\
\hline$\chi^{2}$ value & & & & & 3.951 \\
\hline$P$ value & & & & & 0.047 \\
\hline
\end{tabular}

Values are $n(\%)$.

Table 6 Comparison of the quality of life during the three-month follow-up

\begin{tabular}{lc}
\hline Group & GQOLI-74 score (point) \\
\hline Study group $(n=90)$ & $330.15 \pm 30.07^{\#}$ \\
Control group $(n=90)$ & $267.37 \pm 21.19$ \\
t-value & 16.190 \\
$P$ value & 0.000 \\
\hline
\end{tabular}

Values are mean \pm SD. ${ }^{*} \mathrm{P}<0.05$ vs. control group. GQOLI-74; Generic Quality of Life Inventory-74.

study group was significantly higher than that in the control group during the 3-month follow-up.

\section{Discussion}

With the change of environment, diet structure, and lifestyle, the number of cardiovascular diseases in China has increased significantly, which not only damages the physical and mental health of Chinese residents, but also increases the burden on families and society in general (14). A common cardiovascular disease, CHD is an important cause of death in the elderly in China. The lack of selfrecognition of CHD among the elderly is compounded by their frequent unwillingness to see the doctor despite experiencing pain. The situation is also related to the low compliance caused by the lack of correct disease cognition (15-17). Scientific, reasonable, and standardized health education can be applied to deepen the patients' disease cognition, so that the patients will approach the disease with an improved attitude, cooperate with doctors for treatment, and take actions to benefit their own health. This delays disease progression, improves cardiac function, reduces adverse events, and ameliorates prognosis.

At present, the routine health education model is still traditional. In this model, patients learn in a passive and singular way, which causes low uptake of knowledge. Although the traditional method achieves some results, it is difficult to establish good expectations. With the evolving modern medical model, as well as the further investigation and analysis of the health needs of elderly patients with CHD by clinical scholars, it is believed that diversified and staged health education on the basis of mastering the clinical characteristics of the individual patient, can make up for the shortcoming of routine health education, and satisfy the needs of patients, so as to correct their misunderstanding of their own disease, and enhance their personal health awareness (18).

The purpose of our study was to further clarify the advantages of diversified and staged health education in elderly patients with CHD. In this study, we found that the knowledge mastery of CHD in the study group was higher than that in the control group, indicating that the routine health education model caused limited acceptance of accurate information and did not meet the clinical needs of the patients. On the contrary, diversified and staged health education improved the patients' understanding of the disease and enhanced their self-care ability. Further, we found that compliance in the study group was higher than 
that in the control group. Patient compliance generally refers to the patient's recognition and execution of the medical orders during the process of medical treatment, and is directly related to the treatment, clinical efficacy, and prognosis. In addition, the incidence of adverse events in the study group was significantly reduced after intervention, and the quality of life was also significantly increased during 3-month follow-up. These results showed that diversified and staged health education meets the needs of different individual patients according to a variety of patient characteristics. For example, the distribution of health education materials can ensure that the content is vividly displayed in front of patients, which improve patients' interest and promote the active uptake of relevant knowledge. Multimedia can attract patients' attention by the combination of images, text, language, and art. Peer education encourages them to listen to the suggestions made by peers of the same age, knowledge background, and similar hobbies, thus facing the disease with an improved attitude in alignment with doctors' treatment. This can prevent the further development and deterioration of the disease, reduce adverse cardiovascular events, so patients can gradually return to normal life and society as soon as possible (19-21). According to the above analysis, diversified and staged health education has good prospects for wider application.

In summary, diversified and staged health education is effective for elderly patients with CHD. This model promotes their mastery of knowledge of the disease, selfcare ability, compliance, reduces the incidence of adverse events to a certain extent, and improves the quality of life. In addition, diversified and phased health education has successfully solved the problems of poor compliance behavior and low self-care ability of elderly patients with coronary heart disease, and solved the one-sided problems existing in conventional health education, and effectively met the individual needs of elderly patients with coronary heart disease. This study had some limitations, such as few other associated reports, insufficient sample size, and imperfect outcome indicators. We encourage deep exploration of the health education status of elderly patients with CHD in the future, in order to clarify the overall effect of diversified and staged health education, enrich the research results, and improve the physical health of elderly patients with CHD.

\section{Acknowledgments}

Funding: This work was supported by the Construction and implementation of training program for community rehabilitation specialist nurses with disabilities based on ICF theory (2020XK034). Thanks go to Guangzhou Yujia Biotechnology Co., Ltd for their help in the field.

\section{Footnote}

Reporting Checklist: The authors have completed the CONSORT reporting checklist. Available at http://dx.doi. org/10.21037/apm-20-1995

Data Sharing Statement: Available at http://dx.doi. org/10.21037/apm-20-1995

Conflicts of Interest: All authors have completed the ICMJE uniform disclosure form (available at http://dx.doi. org/10.21037/apm-20-1995). The authors have no conflicts of interest to declare.

Ethical Statement: The authors are accountable for all aspects of the work in ensuring that questions related to the accuracy or integrity of any part of the work are appropriately investigated and resolved. The included cases were approved by the Ethics Committee of Hunan Provincial People's Hospital. All procedures performed in this study involving human participants were in accordance with the Declaration of Helsinki (as revised in 2013). Informed consent was taken from all the patients.

Open Access Statement: This is an Open Access article distributed in accordance with the Creative Commons Attribution-NonCommercial-NoDerivs 4.0 International License (CC BY-NC-ND 4.0), which permits the noncommercial replication and distribution of the article with the strict proviso that no changes or edits are made and the original work is properly cited (including links to both the formal publication through the relevant DOI and the license). See: https://creativecommons.org/licenses/by-nc-nd/4.0/.

\section{References}

1. Marasigan V, Perry I, Bennett K, et al. Explaining the fall in Coronary Heart Disease mortality in the Republic of Ireland between 2000 and 2015 - IMPACT modelling study. Int J Cardiol 2020;310:159-61.

2. Arkhipova NS, Popova EK, Popov IO. Prevalence and Intensity of Smoking in Older Patients with Coronary Heart Disease Living in the Extreme North. Adv Gerontol 
2019;9:346-51.

3. Mykkänen L, Laakso M, Pyörälä K. High plasma insulin level associated with coronary heart disease in the elderly. Am J Epidemiol 1993;137:1190-202.

4. Yan-Hui C, Wei BI. Effect of Psychological Nursing and Health Education on Elderly Patients with Coronary Heart Disease and Angina Pectoris. Guide of China Medicine 2017;15:225-6.

5. Xin W. Research on Effect of Health Education in the Predictive Healthcare and Disease Control of Patients with Coronary Heart Disease. World Journal of Complex Medicine 2017;2.

6. Xiangli S, Mingxia G, Dan W. Role of Health Education in the Care of Patients With Coronary Heart Disease in the Elderly. China Continuing Medical Education 2015;007:216-7.

7. Chunhong G, Kewen M. Effect of primary caretakers' health education on the quality of life in elderly patients with coronary heart disease undergoing percutaneous coronary intervention. Nursing of Integrated Traditional Chinese and Western Medicine 2019;005:P.14-7.

8. Xuefei D, Hui Y, Pan L, et al. The Effect of Health Education by the Delphi Method to Elderly Patients With Coronary Heart Disease. China Continuing Medical Education 2018;010:196-8.

9. Li-ying D, Yun-hong X. Effect of homogeneous medical health education model on life style of patients with coronary heart disease after PCI. Journal of Bengbu Medical College 2019;44:123-5+9.

10. Jian-qin J, Ya-fang Y. Application of cardiac rehabilitation education in cardiac rehabilitation of patients with coronary heart disease Health Research 2019;039:270-2,7.

11. Wu X, Geng YJ, Chen Z, et al. Pulse pressure correlates with coronary artery calcification and risk for coronary heart disease: a study of elderly individuals in the rural region of Southwest China. Coron Artery Dis 2019;30:297-302.

12. Ping L, Shuyuan H. Study of the Relationship Between Living Quality with Health Education in Senile Patients with Coronary Heart Disease. Heilongjiang Nursing Journal 2001:1-2.

Cite this article as: Shan Z, Huang H, Tang S. Effect of diversified and staged health education on the compliance of elderly patients with coronary heart disease. Ann Palliat Med 2020;9(6):4074-4080. doi: 10.21037/apm-20-1995
13. Interventional Cardiology group, Chinese Society of Cardiology, Atherosclerosis and Coronary Heart Disease Group, Chinese Society of Cardiology, Professional Committee on Thrombosis Prevention and Treatment, Chinese College of Cardiovascular Physicians Medical Doctor Association, et al. Guidelines for the Diagnosis and Treatment of Stable Coronary Heart Disease. Chinese Journal of Cardiology 2018;46:680-94.

14. Kheiri B, Abdalla A, Osman M, et al. Vitamin D deficiency and risk of cardiovascular diseases: a narrative review. Clin Hypertens 2018;24:9.

15. DeBoer M, Filipp S, Gurka M. SUN-064 Associations of a Metabolic Syndrome Severity Score with Future Coronary Heart Disease (CHD) and Diabetes in Fasting vs. NonFasting Individuals. J Endocr Soc 2019;3:SUN-064.

16. Murray MK, Bode K, Whittaker P. Gender-specific associations between coronary heart disease and other chronic diseases: cross-sectional evaluation of national survey data from adult residents of Germany. J Geriatr Cardiol 2019;16:663-70.

17. Li-ran W. Survey Research on Hospital Infection Factor in Elderly Patients with Coronary Heart Disease. China Health Industry 2016;13:66-8.

18. Zhu KF, Wang YM, Zhu JZ, et al. National prevalence of coronary heart disease and its relationship with human development index: A systematic review. Eur J Prev Cardiol 2016;23:530-43.

19. Hilleary RS, Jabusch SM, Zheng B, et al. Gender disparities in patient education provided during patient visits with a diagnosis of coronary heart disease. Womens Health (Lond) 2019;15:1745506519845591.

20. Ding N, Wang X, Tucker KL, et al. Dietary patterns, bone lead and incident coronary heart disease among middleaged to elderly men. Environ Res 2019;168:222-9.

21. Floud S, Balkwill A, Moser K, et al. The role of healthrelated behavioural factors in accounting for inequalities in coronary heart disease risk by education and area deprivation: prospective study of 1.2 million UK women. BMC Med 2016;14:145.

(English Language Editor: J. Jones) 